\title{
Temperature variations in sintering ovens for metal ceramic dental prostheses. Non-destructive assessment using OCT
}

\author{
C. Sinescu ${ }^{1}$, A. Bradu ${ }^{2}$, V.-F. Duma ${ }^{* 3,4}$, F. I. Topala ${ }^{1}$, M. L. Negrutiu ${ }^{1}$, A. Gh. Podoleanu ${ }^{2}$ \\ ${ }^{1}$ Faculty of Dentistry, Victor Babes Medicine and Pharmacy University of Timisoara, \\ 2A Eftimie Murgu Place, Timisoara 300070, Romania \\ ${ }^{2}$ Applied Optics Group, School of Physical Sciences, University of Kent, \\ Canterbury, CT2 7NH, UK \\ ${ }^{3} 3 \mathrm{OM}$ Optomechatronics Group, Aurel Vlaicu University of Arad, 77 Revolutiei Ave., \\ Arad 310130, Romania \\ ${ }^{4}$ Doctoral School, Polytechnic University of Timisoara, 1 Mihai Viteazu Ave., Timisoara 300222, \\ Romania
}

\begin{abstract}
We present a recent investigation regarding the use of optical coherence tomography (OCT) in the monitoring of the calibration loss of sintering ovens for the manufacturing of metal ceramic dental prostheses. Differences in the temperatures of such ovens with regard to their specifications lead to stress and even cracks in the prostheses material, therefore to the failure of the dental treatment. Evaluation methods of the ovens calibration consist nowadays of firing supplemental samples; this is subjective, expensive, and time consuming. Using an in-house developed swept source (SS) OCT system, we have demonstrated that a quantitative assessment of the internal structure of the prostheses, therefore of the temperature settings of the ovens can be made. Using en-face OCT images acquired at similar depths inside the samples, the differences in reflectivity allow for the evaluation of the differences in granulation (i.e., in number and size of ceramic grains) of the prostheses material. Fifty samples, divided in five groups, each sintered at different temperatures (lower, higher, or equal to the prescribed one) have been analyzed. The consequences of the temperature variations with regard to the one prescribed were determined. Rules-of-thumb were extracted to monitor objectively, using only OCT images of currently manufactured samples, the settings of the oven. The method proposed allows for avoiding producing prostheses with defects. While such rules-of-thumb achieve a qualitative assessment, an insight in our on-going work on the quantitative assessment of such losses of calibration on dental ovens using OCT is also made.
\end{abstract}

Keywords: Biomedical imaging, Dental Medicine, Optical Coherence Tomography (OCT), metal ceramic dental prostheses, sintering ovens, non-destructive testing (NDT), temperature monitoring, effects of sintering temperatures.

\section{INTRODUCTION}

Sintering of dental ceramics for the manufacuring of prosthesis is influenced by the highest temperature reached and by the time interval and cycle of the thermal treatment of the samples in the dental oven [1-5]. The issue is that a loss of calibration of dental ovens for sintering different types of prosthesis can happen in an unexpected way and can impact negatively numerous prosthesis, as tenths or hundreds of such dental constructs can be manufactured in such an oven every day. Although some dental ovens auto-calibrate themselves every time they are turned on - such as VITA ovens [6] -, most of them do not have such capabilities; also those that have them are more expensive.

The consequence of firing dental ceramics at a different temperature than the normal one prescribed by the manufacturer can be the occurence of fissures, affecting the mechanical (but also the esthetic properties) of the material, resulting for example in chipping of prosthetic constructs [7-9].

For dental ovens that do not auto-calibrate themselves, manufacturers reccomend the dental technicians to fire supplemental samples, using the purest available porcelain. By evaluating visually the result, an „,assessment” can then be done regarding the maximum temperature reached inside the oven. It is obvious that such a method is highly subjective, costly (as it implies supplemental samples), and depends entirely on the experience of the technician; highly experienced operators are thus necessary.

The aim of our direction of research has been in this respect to replace the above method with an objective one, with no supplemental samples fired - if possible. We have considered and analyzed several possible methods that could be used for this: 
(i) Scanning Electron Microscopy (SEM) has a high resolution, but it requires an expensive and massive equipment, which is not currently available in a dental workshop. The necessary sectioning of dental samples may also affect from the very beginning the investigation of the granulation of the ceramics using SEM.

(ii) Micro-CT also has a good resolution, but it is an invasive technique, the equipment os also not currently available in a dental workshop.

(iii) Cone Beam Computer Tomography (CBCT), as well as the commonly used dental radiography do not have enough resolution to image the granulation of the ceramics material for fired samples.

Taking into account the disadvantages of the above methods, we have considered, in order to make such assessments, a method that uses infrared laser radiation to investigate the samples, Optical Coherence Tomography (OCT). OCT is a biomedical imaging techniquebased on the principles of low coherence interferometry, that has been initially developed for ophthalmology, especially for studies of the retina and cornea [10-13]; it has further on expanded towards imaging the skin [14], as well as the oral cavity, for both hard and soft tissue [15-19]. While OCT is being utilized in an increasing area of such biomedical applications, it has also begun to be used extensively in Non-Destructive Testing (NDT) of materials, both refractive (for which cross sections/B-scans can be provided - a major advantage of OCT [2026]) and reflective (i.e., metallic, for which the topography of material surfaces can be obtained [27, 28]).

The penetration depth of OCT is limited to about $1.5 \mathrm{~mm}$ (especially in hard tissue), while its typical axial resolution is around $10 \mu \mathrm{m}$ (although resolutions of $2 \mu \mathrm{m}$ are also available [29]). The question is if these characteristics are suffcient to assess the temperature variations in dental ovens, by studying ceramics granulation inside the samples. The aim of the study is also to obtain the necessary rules-of-thumb to complete such assessments.

\section{OCT STUDY OF METAL CERAMIC DENTAL PROSTHESES}

An in-house developed Swept Source (SS)-OCT system has been used in this research. The schematics of this system was described in detail in [30, 31].

Fifty metal ceramic dental prosthesis corresponding to the first maxillary incisor were manufactured (Fig. 1), using Duceram Kiss ceramics (DeguDent GmbH (a Dentsply Sirona Company), Hanau-Wolfgang, Deutschland).

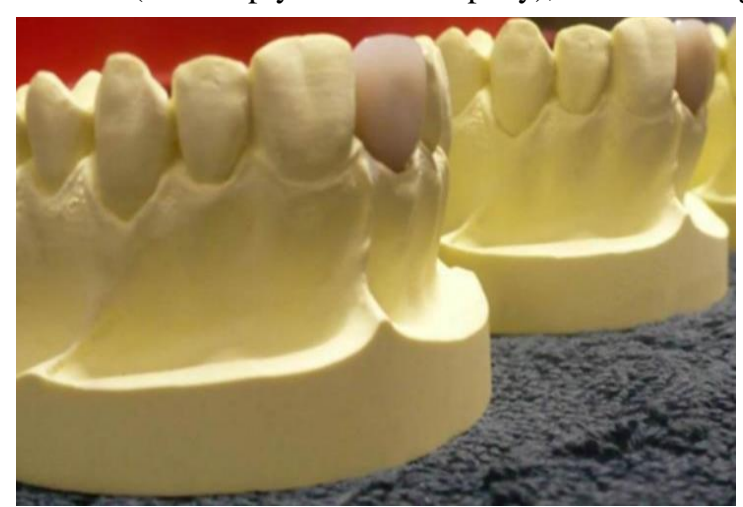

Figure 1. Preparation of the metal ceramic samples - first maxillary incisor made of Duceram Kiss ceramics [30]. 

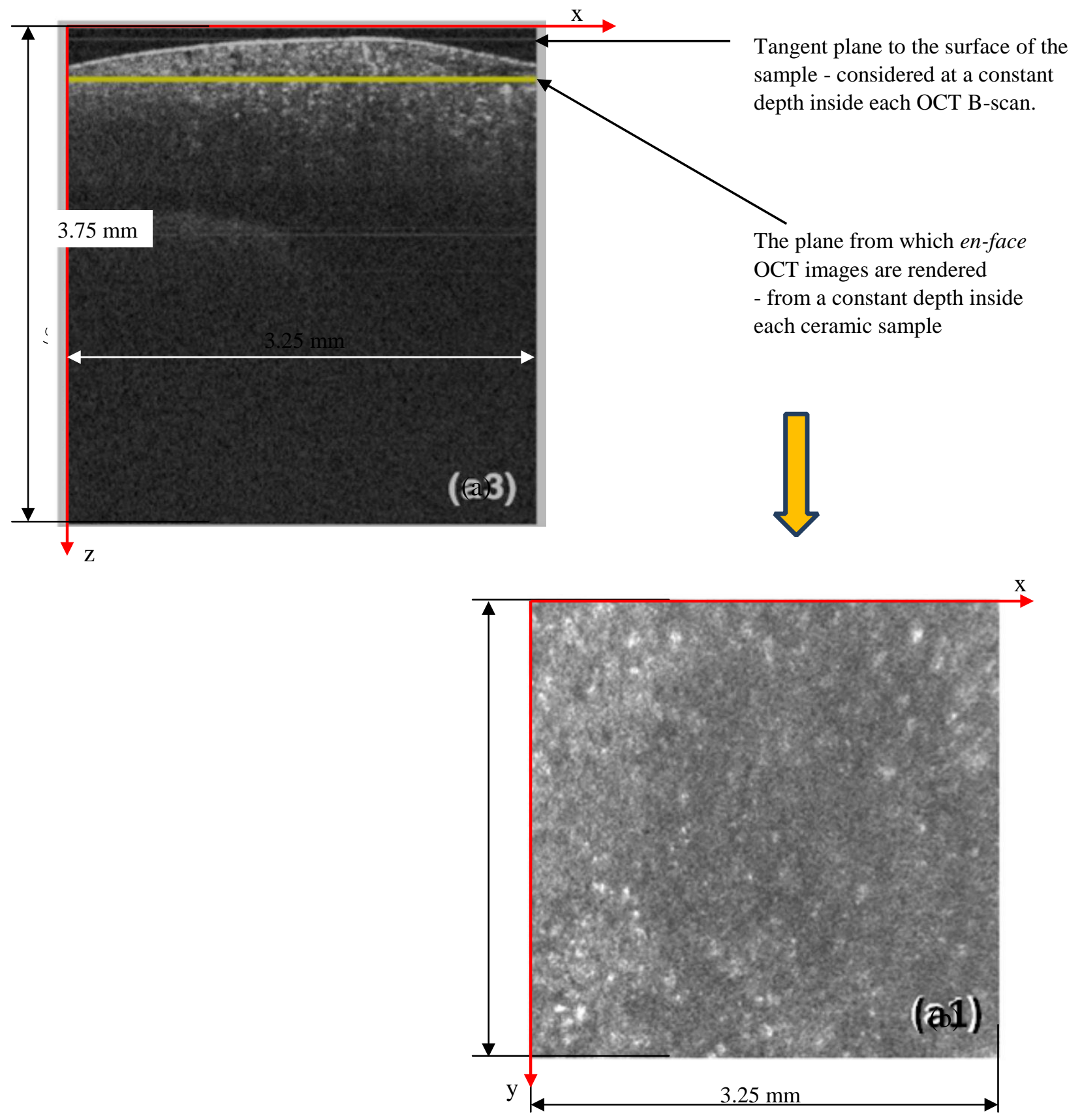

Figure 2. (a) OCT B-scan/cross-section inside a metal ceramic dental prostheses sintered at a temperature $100^{\circ} \mathrm{C}$ lower than the normal one prescribed by the manufacturer (Group L100 in the present study [31]). The dimensions of the image are: $3.25 \mathrm{~mm}$ in the $\mathrm{x}$-direction (parallel to the surface of the sample) and $3.75 \mathrm{~mm}$ in the $\mathrm{z}$ direction (in-depth with regard to the surface of the sample). (b) OCT C-scan/en-face image - taken at a constant depth inside the metal ceramic dental prostheses from this Group L100.

The choice of this material was made based on its good mechanical and esthetic properties [31]; these specific prostheses (corresponding to the first maxillary incisor) were manufactured due to how often they are utilized by patients in dental medicine.

The fifty samples were divided in five groups: Group N, with samples sintered at $930^{\circ} \mathrm{C}-$ the normal temperature prescribed by the manufacturer; Group $\mathbf{L 3 0}$, with samples sintered at $900^{\circ} \mathrm{C}$, with $30^{\circ} \mathrm{C}$ below the prescribed temperature; Group L100, with samples sintered at $830^{\circ} \mathrm{C}$, with $100^{\circ} \mathrm{C}$ bellow the prescribed temperature; Group H30, with samples sintered at $960^{\circ} \mathrm{C}$, with $30^{\circ} \mathrm{C}$ above the prescribed temperature; Group H50, with samples sintered at $980^{\circ} \mathrm{C}$, with $50^{\circ} \mathrm{C}$ above the normal prescribed temperature. 
B-scans/cross sections in the dental material were used, as shown in the example considered in Fig. 2(a), to select the depth from which C-scans/en-face images were obtained - see the example in Fig. 2(b) - for each sample, as described in detail in [31].

For each of the above groups, the B-scans proved to be less relevant in comparison with en-face OCT images - for the assessment of the temperature level in the oven. The latter clearly show a good, uniform granulation for Group $\mathbf{N}$ samples, while for samples from Group L100 and Group L30 they show darker zones that correspond to unsufficiently baked ceramics. In contrast, Group H30, and especially Group H50 samples display much brighter areas and spots, which demonstrate more numerous, larger ceramic grains, and even defects for the highest considered sintering temperature, defects that are sources of cracks, and thus of the destruction of these dental prosthesis - and of failure of th dental treatment [31].

A clear assessment was thus demonstrated to be possible using OCT imaging (specifically, en-face images), in a fast, nondestructive manner, with no supplemental samples fired, i.e. using only prosthesis currently manufactured.

However, the above assessment was still only quantitative. To achieve quantitative assessments, in the following study we have proceeded to an analytical approach [32], based on the reflectivity graphs that can be obtained from the en-face OCT images like the one in Fig. 2(a).

\section{MATHEMATICAL MODELING OF THE REFLECTIVITY GRAPHS}

The reflectivity graphs obtained from en-face OCT images produce, considering an average of such graphs, reflectivity curves - as shown in the example in Fig. 3 for a Group L100 sample; we have obtained such graphs and curves for each of the five groups described above [32].
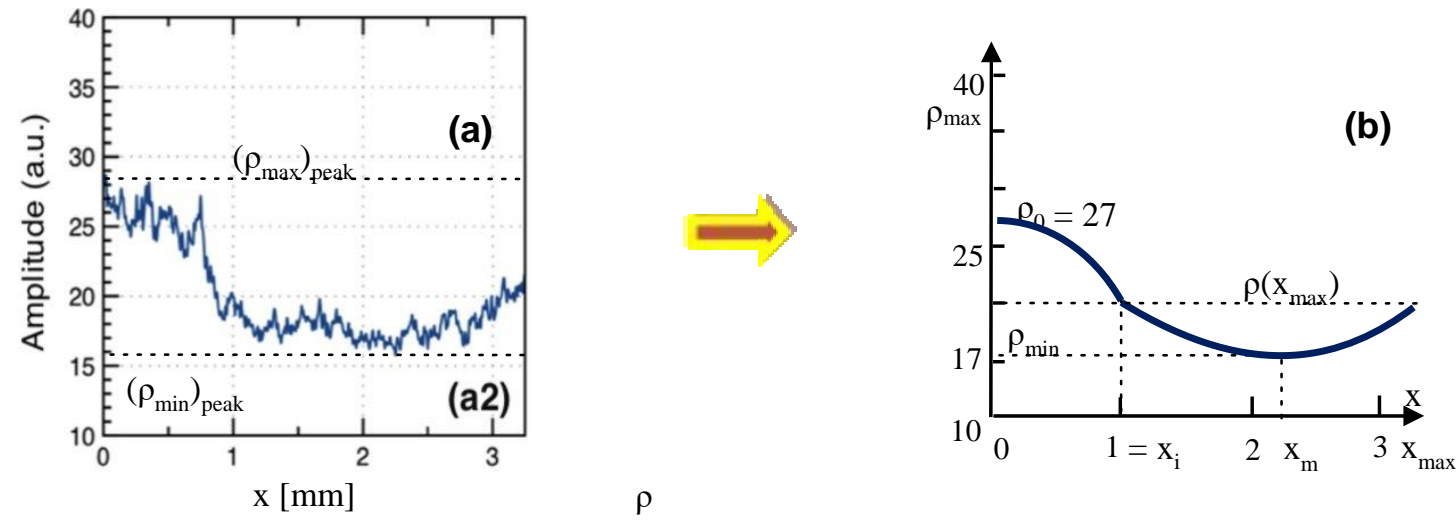

Figure 3. (a) Example of a reflectivity graph obtained using MATLAB in [31] from an en-face OCT image of metal ceramic dental prostheses - Group L100, for samples pressed at $830^{\circ} \mathrm{C}$ (i.e., with $100^{\circ} \mathrm{C}$ bellow the normal sintering temperature recommended by the manufacturer); (b) reflectivity curve, obtained as an average of the reflectivity graph in (a) [32].

A mathematical modelling of the reflection curves can be made in the simplest way with parabolic functions. Thus, for the example considered in Fig. 3, for $x \in\left[0, \mathrm{x}_{\mathrm{i}}\right)=[0,1)$, the following function is obtained:

$$
f(x)=\frac{\rho_{i}-\rho_{0}}{x_{i}^{2}} x^{2}+\rho_{0}
$$

For $x \in\left[x_{i}, x_{\max }\right)=[1,3.25)$, the function is

$$
g(x)=\frac{4\left(\rho_{i}-\rho_{\min }\right) x\left(x-x_{i}-x_{\max }\right)}{\left(x_{\max }-x_{i}\right)^{2}}+\frac{\rho_{i}\left(x_{i}+x_{\max }\right)^{2}-4 \rho_{\min } x_{i} x_{\max }}{\left(2 x_{M}-x_{m}\right)^{2}}
$$

therefore, using the parameters in Fig. 3, the coefficients of the above functions can be obtained; thus

$$
f(x)=3 x^{2}+27
$$

and 


$$
g(x)=2.37 x^{2}-10.07 x+361.25
$$

The first derivatives of these functions can also be obtained; they represent the gradients of reflectivity in the en-face OCT images, therefore they are a measure of the ceramics granulation in this plane.

$$
\frac{d f}{d x}(x)=\frac{4\left(\rho_{i}-\rho_{0}\right)}{x_{i}^{2}} 2 x=6 x
$$

and

$$
\frac{d g}{d x}(x)=\frac{4\left(\rho_{i}-\rho_{\min }\right)\left(2 x-x_{i}-x_{\max }\right)}{\left(x_{\max }-x_{i}\right)^{2}}=5.74 x^{2}-10.07
$$

The second derivatives of the reflectivity functions can also be easily obtained, but they are less relevant from the point of view of the analysis.

Different parameters can be obtained from curves like the one in Fig. 3, as fully developed in [321].

\section{CONCLUSIONS}

We demonstrated that OCT can be used to complete the assessment of temperature variations inside dental ovens. Both the qualitative and the quantitative analysis developed, in [31] and [32], respectively, have been briefly presented. Our ongoing work has fully completed these analysis and rules-of-thumb have been extracted for these assessments [31, 32]. Future work in our groups includes such analysis in the oral cavity, on prostheses already set in place, with fast-imaging OCT systems equipped with handheld scanning probes [25, 26, 29, 33].

\section{ACKNOWLEDGMENTS}

This study is supported by the Romanian National Authority for Scientific Research, through CNDI-UEFISCDI project PN-III-P2-2.1-PTE-2016-0181 (http://3om-group-optomechatronics.ro/) and by the European Union through the European Regional Development Fund under the Competitiveness Operational Program (BioCell-NanoART = Novel Bio-inspired Cellular Nano-architectures, POC-A1-A1.1.4-E 30/2016). A. Bradu and A. Podoleanu acknowledge the support of the European Research Council [Grant 249889 (http://erc.europa.eu)] and EPSRC [REBOT, grant EP/N019229/1]. A. Podoleanu is also supported by the NIHR Biomedical Research Centre at Moorfields Eye Hospital NHS Foundation Trust and UCL Institute of Ophthalmology, by the Royal Society Wolfson Research Merit Award, Innovation Fund Denmark, ShapeOCT 4107-00011A and the ERC ADASMART Proof of concept 754695680879 and UBAPHODESA Marie Curie European Industrial Doctorate, 607627.

\section{REFERENCES}

[1] Rosolowaki, J. H., Greskovich, C., "Theory of the dependence of densification on grain growth during intermediate stage sintering," J. Amer. Ceram. Soc. 58, 177-182 (1975).

[2] Anusavice, K.J. and Lee, R.B., "Effect of firing temperature and water exposure on crack propagation in unglazed porcelain," J. Dent. Res. 68, 1075-1081 (1989).

[3] Gavriliu, G. and Tardei, C., "Influence of the sintering atmosphere on the compacting of high alumina ceramics," Proceedings of the 7th International Meeting on Modern Ceramics Technologies, Montecatini Terme, Italy, Elsevier, Amsterdam (1991).

[4] Cheung, K.-C., "Effect of sintering time and temperature on dental porcelain porosity," http://hdl.handle.net/10722/33304, (1999).

[5] Sailer, I., Feher, A., Filser, F., Gauckler, L.J., Luthy, H., Hammerle, C.H.F., "Five-year clinical results of zirconia frameworks for posterior fixed partial, "Int. J. Prosthodont. 20, 383-388 (2007).

[6] VITA. Available online: http://vitanorthamerica.com/products/equipment/vacumat-6000-m (accessed on 23/03/2017).

[7] Tsalouchou, E., Cattel, M.J., Knowles, J.C., Pittayachawan, P., Mcdonald, A., "Fatigue and fracture properties of yttria partially stabilized zirconia crown systems," Dent. Mater. 24, 308-318 (2008).

[8] Arango, S.S., Vargas, A.P., Escobar, J.S., Monteiro, F.J., Restrepo, L.F., "Medellin: Dyna. Ceramics for dental restorations - An Introduction," 77, 2636 (2010).

[9] Craciunescu, E., Sinescu, C., Negrutiu, M.L., Pop, D.M., Lauer, H.-C., Rominu, M., Hutiu, Gh., Bunoiu, M., Duma, V.-F., and Antoniac, I., "Shear Bond Strength Tests of Zirconia Veneering Ceramics after Chipping Repair," J. of Adhesion Science and Technology 30, 666-676 (2016). 
[10]Huang, D., Swanson, E. A., Lin, C. P., Schuman, J. S., Stinson, W. G., Chang, W., Hee, M. R., Flotte, T., Gregory, K., Puliafito, C. A., and Fujimoto, J. G., “Optical coherence tomography," Science 254(5035), 1178-1181 (1991).

[11]Wojtkowski, M., "High-speed optical coherence tomography: basics and applications," Appl. Opt. 49, D30-D61 (2010).

[12]Drexler, W., Liu, M., Kumar, A., Kamali, T., Unterhuber, A., and Leitgeb, R.A., "Optical coherence tomography today: speed, contrast, and multimodality," J. Biomed. Opt. 19, 071412 (2014).

[13]Braaf, B., Donner, S., Nam, A.S., Bouma, B.E., and Vakoc, B.J., "Complex differential variance angiography with noise-bias correction for optical coherence tomography of the retina, “ Biomed. Opt. Express 9(2), 486-506 (2018).

[14]Lee, K.-S., Zhao, H., Ibrahim, S. F., Meemon, N., Khoudeir, L., and Rolland, J. P., “Three-dimensional imaging of normal skin and nonmelanoma skin cancer with cellular resolution using Gabor domain optical coherence microscopy," J. Biomed. Opt. 17(12), 126006 (2012).

[15]Feldchtein, F., Gelikonov, V., Iksanov, R., Gelikonov, G., Kuranov, R., Sergeev, A., Gladkova, N., Ourutina, M., Reitze, D., and Warren, J., "In vivo OCT imaging of hard and soft tissue of the oral cavity," Opt. Express 3, 239-250 (1998).

[16]Epstein, J., Zhang, L., Rosin, M., “Advances in the diagnosis of oral premalignant and malignant lesions,” J. Can. Dent. Assoc. 68, 617-621 (2002).

[17]Wilder-Smith, P., Holtzman, J., Epstein, J., Le, A., “Optical diagnostics in the oral cavity: an overview”, Oral Diseases 16(8), 717-728 (2010).

[18]Oancea, R., Bradu, A., Sinescu, C., Negru, R. M., Negrutiu, M. L., Antoniac, I., Duma, V.-F., and Podoleanu, A. Gh., "Assessment of the sealant/tooth interface using optical coherence tomography," J. of Adhesion Science and Technology 29(1), 49-58 (2015).

[19]Sinescu, C., Negrutiu, M. L., Bradu. A., Duma, V.-F., and Podoleanu, A. Gh., "Noninvasive quantitative evaluation of the dentin layer during dental procedures using Optical Coherence Tomography," Computational and Mathematical Methods in Medicine, Paper ID 709076 (2015).

[20]Jones, R.S., Staninec, M., Fried, D., “Imaging artificial caries under composite sealants and restorations,” J. Biomed. Opt. 9, 1297-1304 (2004).

[21]Isfeld, D.M., Aparicio, C., Jones, R.S., “Assessing near infrared optical properties of ceramic orthodontic brackets using crosspolarization optical coherence tomography,” J. Biomed. Mater. Res. B Appl. Biomater. 102, 516-523 (2014).

[22]Dsouza, R., Subhash, H., Neuhaus, K., Kantamneni, R., McNamara, P.M,; Hogan, J., Wilson, C., Leahy, M., "Assessment of curing behavior of light-activated dental composites using intensity correlation based multiple reference optical coherence tomography," Lasers Surg, Med. 48, 77-82 (2016).

[23]Han, S.-H., Sadr, A., Tagami, J., Park, S.-H., "Non-destructive evaluation of an internal adaptation of resin composite restoration with swept-source optical coherence tomography and micro-CT," Dental Materials 32, E1-E7 (2016).

[24]Canjau, S., Todea, C., Negrutiu, M.L., Sinescu, C., Topala, F.I., Marcauteanu, C., Manescu, A., Duma, V.-F., Bradu, A., and Podoleanu, A. Gh., "Optical Coherence Tomography for Non-Invasive ex vivo Investigations in Dental Medicine - a Joint Group Experience (Review), “ Modern Technologies in Medicine 7(1), 97-115 (2015).

[25]Demian, D., Duma, V.-F., Sinescu, C., Negrutiu, M. L., Cernat, R., Topala, F. I., Hutiu, Gh., Bradu, A., and Podoleanu, A. Gh., "Design and testing of prototype handheld scanning probes for optical coherence tomography," Journal of Engineering in Medicine 228(8), 743-753 (2014).

[26]Duma, V.-F., Dobre, G., Demian, D., Cernat, R., Sinescu, C., Topala, F. I., Negrutiu, M. L., Hutiu Gh., Bradu, A., and Podoleanu, A. Gh., "Handheld scanning probes for optical coherence tomography," Romanian Reports in Physics 67(4), 13461358 (2015).

[27]Hutiu, Gh., Duma, V.-F., Demian, D., Bradu, A., and Podoleanu, A. Gh., "Surface imaging of metallic material fractures using optical coherence tomography," Applied Optics 53(26), 5912-5916 (2014).

[28]Hutiu, Gh., Duma, V.-F., Demian, D., Bradu, A., and Podoleanu, A. Gh., "Assessment of ductile, brittle, and fatigue fractures of metals using optical coherence tomography," Metals 8(2), 117 (2018).

[29]Cogliati, A., Canavesi, C., Hayes, A., Tankam, P., Duma, V.-F., Santhanam, A., Thompson, K.P., and Rolland, J. P., "MEMSbased handheld scanning probe with pre-shaped input signals for distortion-free images in Gabor-Domain Optical Coherence Microscopy," Optics Express 24(12), 13365-13374 (2016).

[30]Podoleanu, A. Gh. and Bradu, A., "Master-slave interferometry for parallel spectral domain interferometry sensing and versatile 3D optical coherence tomography," Opt. Express 21, 19324-19338 (2013).

[31]Sinescu, C., Bradu, A., Duma, V.-F., Topala, F., Negrutiu, M.L., and Podoleanu, A. Gh., "Effects of the temperature variations in the technology of metal ceramic dental prostheses: Non-destructive detection using optical coherence tomography," Applied Sciences 7(6), 552 (2017).

[32]Duma, V.-F., Sinescu, C., Bradu, A., Podoleanu, A. Gh., "Optical Coherence Tomography Investigations and Modeling of the Sintering of Dental Pressed Ceramic Crowns," Ceramics International 44, (2018).

[33]Monroy, G.L., Won, J., Spillman, D.R., Dsouza, R., and Boppart, St.A., "Clinical translation of handheld optical coherence tomography: practical considerations and recent advancements," J. Biomed. Opt. 22(12), 121715 (2018). 